the shaft and free extremity of the hair, and not arising from, or, indeed, affecting, the root or follicle in any wayas in tinea tonsurans, or, as has been described, but as we have never been able to find, in sycosis. For a second specimen of a form of disease of the hair-shaft we are indebted to the courtesy of Dr. Stanislaus Poniklo, Assistant Professor of Pathology in the University of Cracow. Dr. Poniklo, in forwarding the specimens, states that they were taken from the moustache of a man aged forty, that he has been unable to satisfy himself of the presence of any fungoid elements, and that the morbid condition appeared to him to correspond with the trichorexis nodosa of the German pathologists. On examining these hairs we find in many regular and symmetrical cone-like enlargements of the shaft, and in some brush-like splitting of the ends. There is, however, no incrustation of the shaft, no masses of cells adhering to the outer cortex. The cortical nodes are seen under the microscope to be due to the separation of the fibre cells of the cortex, and their rupture at the point of greatest tension, the greatest curvature. But the most careful scrutiny fails to detect sporules or mycelium of fungus, either in the hairshaft itself or adherent to its exterior. We may now compare these conditions with those previously recorded by other observers.

Kaposi, in vol. iii. of Hebra's work on "Diseases of the Skin," mentions, among other affections of the hair, one that oceurs in the form of nodes, for which he proposes the name of Trichorexis nodosa. He says they are found on the hairs of the beard and moustache, as transparent or glistening conical swellings, occurring at intervals, like pearls on a string. On close inspection the nodes are found to belong to the hairs. Under the microscope, the following conditions are found to occur with the greatest regularity :1. A node corresponds to a simple spindle-shaped swelling of the shaft of the hair. Or, 2. In the centre of the spindleshaped swelling the medulla of the hair itself is swollen out in the form of a spindle. 3. At another part, the node has burst in such a manner that at the seat of the greatest curvature of the conical swelling the cortical substance of the hair has given way, and the spindle-shaped cells of the lower half of the cone project free upward and outwards, whilst those of the upper half look downwards and outwards; so that they are therefore placed one against the other ruggedly, like two besoms, the twigs of each of which have been thrust amongst those of the other, and whose extreme outline in section would form a rhombus. 4. A hair which appears to be terminated by a conical swelling shows microscopically a besom-like end, and this terminal, splitting up represents the lower half, as described, of a conical swelling, which had previously been situated in the continuity of the hair-shaft, and at which this had broken short off. 5. The fibres of the terminal and central tufts. consist of the granular spindle-shaped cells of the cortical substance of the shaft of the hair. 6. There is no trace of any fungus to be seen.

After this careful description of the pathology, Kaposi goes on to say that he cannot assign any cause for the swelling and splitting of the hair, but mentions the fact that Beigel, who wrote on "Swelling and Bursting of the Hairs," 1855, is of opinion that gas is possibly developed in the medullary substance, which at first is itself swollen out and burst by it, and that then the cortical substance is similarly affected.

Dr. Wilks, in his work on Pathology, describes a condition almost identical with the trichorexis nodosa of Kaposi. In a letter published during the discussion on the subject, Dr. Wilks states that he now believes the disease to be parasitic, but he does not give any reasons for his change of opinion.

Dr. Tilbury Fox, in the third edition of his work on Diseases of the 'Skin, mentions in a few words, under the head of Sycosis, a fungous disease of the hair. He says, " it is due to a fungus getting into the root and developing in the shaft after being carried some distance along it." The other condition mentioned in the same paragraph, in which " badly-nourished hairs break off and split up into fibres," probably corresponds to trichorexis nodosa and Dr. Wilks's cases.

MI. Desenne read before the Académie des Sciences a description of piedra, a disease of the hair seen only in Columbia. It occurs in small nodosities visible to the naked eve, and as hard as stone, resisting and even turning the edge of a scalpel. M. Desenne is of opinion that the nodosities are composed of fungous elements. He was unable to find any trace of fungus in the substance of the hair itself.

It. will be seen, then, that while the morbid appearances exhibited in the second case correspond with those described by Kaposi, Beigel, and Wilks, as trichorexis nodosa,"those! observed in the first case, and figured 'in 'the woodcut, "differ' from previously described pathological conditions in severál' essential particulars, 1. They differ from the so-called? trichorexis nosoda in the presence of parasitic growth in the! incrustation of the shaft, by roe-like masses of sporules, and" in the absence of multiple symmetrical nodosities. 2. From? the affection described by Dr. Tilbury Fox as a variety of sycosis, in the limitation of the fungoid elements to the shaft" and to its "exterior, the root and interior 'of the 'shaft being' free, by "the agglomeration of the sporules into roe-like." masses, and, above all; by the absence of any sign of affection of the air-follicle itself or of the adjoining skin. 3. From piedra in the softness of the nodosities, compared with the stony hardness characteristic of that disease.

There would appear," then, to be at least three distinct forms of disease of the hair characterised by nodular enlargement and splitting-viz., the piedra of Columbia, the trichorexis nodosa of the Germans, and a parasitic affection which might, perhaps, be termed tinea nodosa.

$$
\text { ar }
$$

\section{GLIOMA RETINA; EXCISION OF EYE; NO RECURRENCE OF DISEASE AFTER TWO YEARS.}

BY FRANK H. HODGES, F.R.C.S. ED., OPHTHALMIC SURGEON TO THE LEICESTER INFIRMARY.

NELLIE A- aged four, was brought to me on July 19th, 1876. Six weeks previously her mother had noticed a yellowish body within the pupil of the left eye, which she then discovered to be blind. I found the pupil somewhat larger than its fellow, and inactive ; slight ciliary congestion and lachrymation, but no pain ; tension + (?). On looking, into the eye the media, including lens, were seen to be quite, clear ; and, on patient looking downwards and inwards, an opaque, yellowish body, having very much the appearance of wash-leather, and traversed by numerous fine vessels, was seen." : This body had a concave, cupped appearance, and seemed to be separated into two by the vessels, the smaller portion of the tumour being above them. I diagnosed glioma, and advised immediate excision.. 'Dr. Taylor, of Nottingham, saw the case the following day; and wrote to me: "This is clearly a case of glioma, and I should extirpate at once."

On July 25th I excised the eye in the usual manner, dividing the nerve as close to the orbit as possible.

Mr. Priestley Smith, of Birmingham, kindly microscopically examined the tumour for me, and his report is as follows:- "The globe, having been for some time in absolute alcohol, is considerably shrunken, and the sclera is drawn inwards in places, so as to lose its spherical form. The whole of the vitreous chamber is filled with a solid, white, brainlike mass, which under the microscope exhibits the structure of glioma-namely, small round cells of uniform size, with little if any intercellular substance. The extent to which the new growth has compressed the structures which limit its extension, and apparently without invading them, is very remarkable. 'An anterior chamber is entirely wanting. ' The lens is flattened to about one-third of its normal thickness, and is adherent throughout the area of the pupil to the posterior surface of the cornea. In several sections through these structures the anterior capsule, with some lens fibres attached, was torn away from the body of the lens, and remained adherent to the cornea. The iris is tightly compressed between the cornea and lens, and is in some parts, if not universally, adherent to both structures. The position of the ciliary processes is just revealed iby a slight thickening of the black line representing the iris and ' choroid, in which can be discerned, by manipulating "the" cover-glass, the greatly flattened apices of the ciliary pro-" cesses. The equator of the lens is compressed, so as to' form a very acute angle. The suspensory ligament is entire and limits anteriorly the extension of the morbid growth. Elsewhere the tumour appears to be limited by the at 
tenuated choroid and by the optic disc. The optic nerve, $4 \mathrm{~mm}$. long, appears quite healthy."

The results of excision of the globe for glioma, even when performed at an early period of the disease, are not encouraging. Usually an arrest of the disease for a few months only is gained; then recurrence ensues in the divided optic nerve, and rapidly proves fatal. Sir William Jenner has narrated, in his graphic manner, a case of laryngeal diphtheria in which life was saved by tracheotomy. And he remarks, that were the operation to fail a thousand times, he should still feel justified in recommending it in similar conditions; and more especially as a painless death asthenia-is substituted for a distressing one, slow suffocation. I think the same arguments may be forcibly applied to cases of glioma retinæ; for, even if extirpation fails to save life, it will invariably relieve the patient from much terrible suffering.

Leicester.

\section{9 邹tirutor}

\section{HOSPITAL PRACTICE,}

\section{BRITISH AND FOREIGN.}

Nulla autem est alia pro certo noscendi via, nisi quamplurimas et morborum et dissectionum historias, tum aliorum, tum proprias collectas habere, inter se comparare.-Morgagri De Sed. et Caus. Morb., lib. iv. Proœmium.

\section{ST. BARTHOLOMEW'S HOSPITAL.}

DIABETES ; CASES OF DEATH BY SO-CALLED ACETONAMIA; CLINICAC REMARKS.

(Under the care of Dr. Regrnald SoutheY.)

DIABETES is a disease of which the diagnosis is usually easy, although the physiology is a very intricate problem. Two cases in which some uncertainty regarding diagnosis existed before death have lately come under Dr. Southey's care in the hospital, and are sufficiently interesting to merit attention.

CASE 1.-Ed. W-, aged forty-four, travelled up from Sheerness on July 6 th, 1877 , to St. Bartholomew's Hospital, for advice upon indigestion. He was seen by Dr. Gee, who found him so exhausted, cold, and feeble, that he at once admitted him into Luke ward. He was a sallow, emaciated man, with a dry rough skin and dry furred tongue. The heart-sounds were loud and clear, the respiration shallow and feeble. There were no physical signs of lung catarrh, or evidence of lung disease. Sugar had been noticed in his urine, and he acknowledged some polyuria. On July 8th a sample of his urine was examined, which was of sp. gr. 1013, alkaline, straw-coloured, and contained no signs of albumen. Absence of sugar was given as a fact by the house-physician, Mr. Darbishire.

At about 4 o'clock on the morning of the 9th of July the patient's breathing attracted the notice of the nightnurse ; it was noisy and laboured. He got up and went to the closet, and seemed semi-delirious and strange. The house-physician was sent for, and found him at 5 A.M. breathing loudly and stertorously, the respiration being 23 per minute; pulse 106, rather empty, but regular. The heart-sounds were clear. He was not unconscious, but obfuscated, roused when spoken to loudly, but did not remember where he was or what he had been doing. His feet and hands were cold; his pupils acted to light, and the conjunctivæ were sensitive; lips rather blue.

Some ether and ammonia was administered, and, as this did not affect him much, the inhalation of a few drops of nitrite of amyl was essayed; under this he roused up, answered questions better, and said he was in no pain, that he felt all right in himself, and that he had never been taken queer in this manner before. The previous twentyfour hours' urine had been collected; it was acid, clear, straw-coloured, with a specific gravity of 1034, and contained 1.8 per cent. of urea (total, 33.84 grms.) and 12.5 per cent. of sugar (equal to 235 grms.)

Between 8 A.M. and 10 P.M. on July 9th the patient did not pass a drop of urine, and at the latter hour there was none accumulated in his bladder. He had taken milk, beef tea, and fluid nourishment in small quantity throughout the day. His bowels had not acted, and an enema which had been given had been returned unaltered.

Throughout July 9 th and 10 th he remained in a soporous condition, sleeping and breathing heavily, 28 per minute, with blue lips, having cold extremities, and a feeble but regular pulse, 72. For some time he could be roused to take nourishment, then he became profoundly comatose, breathing almost stertorously. Still there were spontaneous movements of his limbs until shortly before his death, and no paralysis was noticed, and probably none existed. The breathing stopped suddenly about 3 P.M., July 10th. No post-mortem examination allowed.

CASE 2.-Honore $\mathrm{H}-$ - aged eleven, a patient of Dr. Slyman, of Camden-town, a delicate, emaciated-looking cbild, under care for badly broken chilblains, was found to be so ill and weak in December, 1878, that a close inquiry was made about her urinary functions, and the urine was found to contain no inconsiderable amount of sugar. The mother had noticed nothing about the child before Dec. 14th, when she had some sickness; but from about this date, at all events, the patient had had frequent micturition, making water about twelve times by day and three times by night. She had also drunk water excessively, and had very often vomited. She was dieted strictly, but as it was not so easy to enforce or carry out the instructions at the patient's house, she was admitted into the hospital on Jan. 3rd last. In addition to her antidiabetic diet, she was ordered a pill containing small doses of belladonna and opium.

As soon as twenty-four hours' urine could be collected, Mr. Heath set about estimating the amount of sugar by the fermentation test. The average quantity passed between Jan. 3rd and Jan. 6th was about five pints per twenty-four hours; sp. gr. 1035. After fermentation with addition of yeast the sp. gr. was reduced to 1010 , so the sugar was estimated roughly at about 25 grains per ounce; therefore 100 fluid ounces would contain 2500 grains, or $5 \mathrm{oz} .10 \mathrm{gr}$. of sugar per diem.

For the first two days after her admission she took a fair amount of nourishment, and was kept warm in bed; still she was very frequently sick. On Jan. 5th she took very little nourishment all day, and was not thought so well She complained of a good deal of pain at times in her stomach. During the night between the 5th and 6 th she became delirious. At midday of the 6th her pulse, which had been 132 and very feeble in the morning, was scarcely to be felt or counted; her respiration was 48 , and her breath was cold; temperature $97^{\circ} 8^{\circ}$. She looked livid and collapsed, lay in a semi-conscious state, from which she could only be momentarily aroused. She could hear and partly understand what was said to her, but answered incorrectly and apathetically. Her condition betokened death by acetonæmia, formerly called glycosæmia or saccharæmia. Nutrient enemata were given ber every three hours, and a draught of aromatic spirits of ammonia, with tincture of capsicum, in camphor-water, every three hours. She was placed at once in as hot a bath as she could bear. After the hot bath and three nutrient enemata she rallied a little. At 2 P.M., Jan. 6th, the pulse could be counted again at the wrist, and she kept a little milk on her stomach. There was no further vomiting after 8 P.M. on the 6th. Her abdomen was slightly tender on pressure; tongue dry and furred. Only two pints and a half of urine were passed between Jan. 6th and Jan. 7th. This was very acid, turbid, yellow-brown coloured, and contained a trace of albumen (one-tenth). There was a suspicion that some tea had been vomited into the vessel containing it. During the night (7th and 8th) she passed into a more profound coma, from which she could not be roused to take anything, and died at 3 A.M. of the 8 th without any struggle or convulsion.

The necropsy showed great emaciation. Broken chiblains on right heel and toes of left foot. The skin was harsh. There were two ecchymoses about the size of a crown-piece upon left tibia. The mucous membrane of the tonsils, larynx, and epiglottis was swollen and cedematous as far as vocal cords, not further down trachea. There was an appearance of tonsillitis on right tonsil, and some enlargement of the cervical glands on right side of neck. The lungs were collapsed naturally, were blood-filled, but not cedematous; they were not diseased. The heart was small, its muscular structure was healthy under microscope. The right ventricle was extremely thin, and the right auricle like thick brown paper. The liver and spleen were normal to all appearance. The kidneys were firm, tough, and congested in area vasculosa. The intestines were normal 